\title{
Introduction: pandemic precarity
}

\author{
Aseem Prakash ${ }^{1}$ \\ Published online: 1 October 2021 \\ ( ) Institute for Social and Economic Change 2021
}

The current literature elaborates on two meanings of precarity. In the seminal works of Judith Butler (2004, 2009), precariousness emerges from social interdependence, and human lives are invariably dependent, conditioned and shaped by other fellow humans. She explains that precarity may originate either through people we know or barely know or not know at all. Thus, precariousness is an ineffaceable part of human existence such that human lives are exposed to the possibility of many different types of vulnerabilities, threats and destructions. There is also an element of differential precarity, that is, all lives are not equally precarious. Butler proposes an ontological shift from an individualism focused protection of life framework to the social and political conditions that translate into precariousness. The other notion of precarity emerges from scholars who primarily work on labour markets in general and informal labour markets in particular. Scholars use the concept of precarity to describe the socio-economic conditions of labour resulting from either the withdrawal or reduction of the state's welfare provisions (Castel 2003, Neilson \& Rossiter 2008, Standing 2011, Casas-Cortes 2014, Lorey 2015). In this understanding, precarity emerges from a combination of various factors such as the non-availability of a stable job, marginal possibility of social mobility, absence of social security entitlements, lack of collective voice, rising debts for basic survival needs, etc.

Pandemic precarity has occurred at a specific historical juncture that uniquely combines the two forms of precarity discussed above. However, social life is not governed by the laws of arithmetic, where two distinct phenomena can be added to produce the sum. Instead, the two phenomena may feed into each other to create a new social reality. The set of papers in this issue document, analyse and understand pandemic precarity triggered by the deadly Corona Virus (2019- nCoV). Indeed, it was perhaps the first real globalisation of a medical emergency where the virus seamlessly travelled, penetrated and infected unconnected people faster than globalised capital or labour could dream of. How can such pandemic precarity be understood?

Pandemic precarity is a unique historical moment in which, while the immediate event triggers the current distress, but the intensity of the impact is also shaped by past and current state policies as well as the historically evolved socio-economic structure. It began once the virus was first detected in the Wuhan province of China and subsequently spread to more than 180 countries with around 210 million confirmed cases and 4.4 million deaths

Aseem Prakash

aseemprakash@gmail.com

1 Professor of Public Policy, School of Public Policy and Governance, Tata Institute of Social Sciences, Hyderabad, India 
(as on $22^{\text {nd }}$ August, 2021-WHO estimates). The unique nature of the virus caused a medical emergency and the prevention of its transmission mandated varied forms of social and economic lockdowns. These lockdowns exacerbated the existing precarity of informal labour and other marginalised sections of the population. The set of papers in this volume highlight the current and past actions of the state that amplified precarity during the pandemic, identify the market conditions and market response to the pandemic that further intensified precarity, and finally, trace how the actions and activities of civil society attempted to address the various types of precarity.

Basheer and Haque, in their paper, examine data from 148 countries to explain that air pollution did intensify the life and spread of the virus. The authors also find a positive association between quality of public health system and past experience of dealing with other health emergency as a cause of low incidence of Covid-19 infections and related deaths. Exploring this argument further, the paper by Pandey and his colleagues examines all available evidence to understand the geographical concentration of Covid-19 cases in India. The article does not find a robust association between the availability of health infrastructure at the state level and high rates of Covid-19 infections and deaths. Instead, the paper argues that the incidence of Covid-19 infection can be better understood by analysing evidence at the district level. In other words, there appears to be a positive association between the high prevalence of Covid-19 infection and certain social determinants such as population density, availability of basic amenities such as drinking water and sanitation in households, demographic factors such as migrant population, elderly population and people with co-morbidities. Due to this, it appears that the Indian cities were stretched beyond their limit in containing the spread of the Covid-19 Virus, especially in informal settlements. Bhide's paper in the volume details the reasons for the latter. She argues that the information deficit (not even a single city in India has comprehensive knowledge of the number of settlements, settlers, their living conditions, availability and quantum of public resources, etc.) constraints the role of planning in cities during normal times, which further exacerbated precarity during the long-drawn pandemic. Moreover, many informal settlements in several cities do not even exist statistically in government records, making such settlers invisible.

With the aggressive spread of the Covid-19 Virus, the Indian health infrastructure came under severe stress. Sundararaman and his colleagues detail the reasons behind the inability of the health system to cope with the rush of Covid-19 cases and deaths. They argue that the present primary care health set-up is only designed to address a few non-communicable and communicable diseases. Without the ability to address a range of diseases, primary health centres are not resilient enough to handle situations like the pandemic and other health emergencies. Further, they point out that surge capacity — an excess redundant capacity that can be urgently activated - of the Indian health system is minimal or nonexistent for handling any health emergency, including the current pandemic. Besides this, India appears to have lacked an adequate disease surveillance system and effective production, procurement and distribution of the essential medical product.

Rising Covid-19 infections and deaths lead to lockdown, which in turn had adverse impacts on the markets. The closure of economic activities not only had severe implications on the economic growth of the country but also translated into the closure of businesses and subsequent job losses. Mamgain's paper in this volume captures the magnitude of job losses in the months following the lockdown. It points out that the worst sufferers were small traders, self-employed, migrant workers, daily wage labourers, youth and women, who primarily work in the informal sector of the Indian economy. Moreover, the recovery rate was seen as very slow when it comes to salaried jobs and youth employment. 
Given the constriction of the market and loss of employment, loss of wages and abysmally slow economic recovery, food security of the poor and other social groups who lost their means of livelihood became a severe cause of worry. How were the food security issues sought to be addressed? The delivery of any welfare entitlement is contingent on the correct identification of the beneficiary whereas its utility is gauged by the quantum of benefits. The central government extended food support to individuals to individual/families having ration cards registered under National Food Security Act (NFSA). Sinha's paper in the volume notes that this initiative left out additional state ration cardholders as well as those who do not have ration cards. She also noted that the extra food grains allocated for migrants did not show much promising off-take. Thus, food precarity, notes Sinha, seems to have been exacerbated by pandemic conditions and the inability of policy guidelines to identify vulnerable individuals/social groups left out by the NFSA. Khan and Bali's paper in this volume notes that the food precarity of children during Covid was caused in part by the closure of mid-day meal schemes during pandemic months. Certain states like Kerala did well and continued with the mid-day meal programme uninterrupted, which in turn drew positive returns. Eventually, the Supreme Court intervened and ordered for the continuation of mid-day school meals and supplementary nutrition to children, pregnant and lactating mothers. Besides food, another dimension of pandemic precarity emerged due to the disruption of routine health services. Bisht and her colleagues argue in this volume that the disruption of health services like routine immunisation, maternal health services, tuberculosis and a host of non-communicable diseases further aggravated the existing inequality and vulnerability. The authors note that given the ongoing privatisation of health care, the social and economically marginalised individuals and groups bore the maximum brunt of ill health besides the problems associated with Covid-19.

How do we understand the role of the state in the midst of various types precarities caused by the pandemic? Sarukkai, in his paper in the volume, responds to the recent call of 'self-reliance'. He makes a distinction between 'self of a nation' and 'national self'. The national self for Sarukkai is an 'imposed quality' in want of creating a hegemonic disposition and is often devoid of lived experience. The self of the nation is born out of the lived experience and acknowledges the complex plurality. The latter connotes that self-reliance cannot be merely about producing goods and services for self-reliance. Instead, self-reliance would mean intellectual freedom where ideas are solely not drawn from the 'west' or the 'past' alone. A view of self-reliance that seeks sufficiency in factory production without intellectual freedom will be antithetical to free, democratic and egalitarian society. Subsequently, Sarkar's paper in this volume puts forth a thesis of 'dominance and hegemony' to explain the character of the state during the time of pandemic. The thesis entails that the state deploys coercive power (for instance, police) but does not face any resistance. In other words, the pandemic brought the state to the centre stage, and the state arrogated absolute power to itself. The state effectively deployed the coercive arm (the police), but the other branches of the executive remained ineffective or weak in addressing the woes unfolded by the pandemic. Such ineffectiveness of governance did not translate into any major protest by citizens. The cultural and other symbols (sound and light etc) used by the government was effective in mobilising citizens towards attesting the viewpoints of the state. However, the paper by Sahoo and Ranjan's paper tries to highlight what actually worked in addressing immediate need of pandemic-induced precarity in the state of Odisha. Their paper highlights that Odisha's relative successful intervention was due to clarity in approach (quickly developing standard operating procedures) addressing information asymmetry about Covid infection, leveraging past experience from various disasters, delegating powers to local institutions so that they can respond to the emergent problem without loss of time, 
strengthening public health systems at an incredible pace, and transferring financial packages and welfare goods to the most vulnerable individuals/social groups. In contrast to the relative successful initiatives, a case study on prisons by Raghavan in this volume points out to the limitations of the governance regimes in taking effective measures towards containing the precarity caused by the pandemic. The essay highlights that the Supreme Court orders to release the prisoners and decongest prisons so as to safeguard the prisoners from the pandemic-induced medical risk was implemented without factoring in the health risk of the prisoners. In other words, the criterion of release as executed was not based on health vulnerability. Instead, the release was based on the reproduction of the dominant discourse that certain prisoners are 'dangerous' and pose a risk to 'law and order' and hence should not be released irrespective of health and co-morbidity conditions. In a similar take, Sapra and her colleague in this volume analyse the ambivalent, knee jerk reaction on the part of the Telangana state to address the woes of migrants who wanted to return to their native places during the lockdown. The essay also captures the role of the judiciary that binds the state government to take urgent measures. The inaction of the state created space for civil society actors to undertake temporary relief and welfare measures for the migrants.

Another space that saw a potentially massive role of civil society was the initiative addressing the mental health issues. Joshi's paper in this volume captures the initiative to address mental health issue spearheaded by an academic institution. Besides informing the initiative's results that sought to address the worsening mental health of individuals, particularly those who come from marginalised socio-economic backgrounds, the paper also reports another critical aspect of pandemic precarity. The paper advocates that these mental health concerns have to be necessarily understood through psycho-social lens. In other words, the paper argues that psychological distress cannot be seen as an autonomous phenomenon but has to be located at the backdrop of 'structural triggers' - food insecurity, lack of shelter, livelihood constraints, violence and inadequate health facilities, etc. The existing inequality and distress due to these triggers got further intensified during the pandemic leading to severe mental health issues. Hence, mental health should be mandatorily seen as a development issue where each impact the other.

Based on the current understanding of precarity and the set of papers presented in the volume discussing various aspects of pandemic precarity, we may briefly outline the meaning and substance of pandemic precarity. Pandemic precarity emerged in the interdependent world where actions and medical conditions in one part of the globe drastically impacted the other. The pandemic affected all domains of human life, not merely job, income or wage conditions. It outlines the impacts of historically evolved social and policy conditions that made the life of some more precarious than others. The latter indicates conditions of the environment, habitation and amenities, structural conditions of labour markets, and statistical gaps that make certain informal settlements, individuals, and occupation groups invisible for policy interventions. These conditions, in turn, have resulted in differential impact of the pandemic and made everyday life more precarious for economically and socially marginalised individuals, individuals from specific aged cohorts and occupation groups. Pandemic precarity also means the incapacity of health infrastructure to address the pandemic triggered and pandemic-induced health problems. The former connotes the medical emergency caused by the immediate pandemic (Covid19) and institutional bottlenecks of health infrastructure to effectively address it. The latter points out to non-availability or inability to access health services for communicable and non-communicable diseases, other than Covid-19 infections, leading to severe health and medical problems and emergencies. The conditions of pandemic also disallow individuals and social groups even to access their social networks, which otherwise would have been 
available to address their everyday woes and problems. In other words, individuals and social groups rely on a variety of resources, including and social and state support that was not available due to pandemic conditions. Last but not least, pandemic precarity also highlighted the serious mental health issues whose cause can be better understood through the adoption of a psycho-social lens.

Despite all problems and constraints, the pandemic has provided an opportunity for the human civilisation to re-imagine the future where each individual's life has the same worth and dignity. In other words, the human mind has to create the political and policy will to structure social and political conditions that are opposed to any form of human-induced precarity.

Funding No funding is provided for the preparation of the manuscript.

\section{Declarations}

Conflict of interest There is no conflict of interest in this work.

\section{References}

Butler J (2004) Precarious life: the powers of mourning and violence. Verso, London

Butler J (2009) Frames of war: when is life grievable? Verso, London

Casas-Cortes M (2014) A genealogy of precarity: a toolbox for rearticulating fragmented social realities in and out of the workplace. Rethink. Marxism 26(2):206-26

Castel R (2003) From manual workers to wage laborers: transformation of the social question. NJ, Transaction Publications, New Brunswick

Lorey I (2015) State of insecurity: government of the precarious. Verso, London

Neilson B, Rossiter N (2008) Precarity as political concept, or, fordism as exception. Theory Cult. Soc. 25(7-8):51-72

Standing G (2011) The precariat: the new dangerous class. Bloomsbury, London

Publisher's Note Springer Nature remains neutral with regard to jurisdictional claims in published maps and institutional affiliations. 